\title{
Requirements for Selection/Development of a Biomaterial
}

\author{
Silvio José Gobbi*1, Vagner João Gobbi ${ }^{1}$ and Ynglid Rocha ${ }^{2}$ \\ ${ }^{1}$ Faculty of Technology, University of Brasilia- UnB, Brazil \\ ${ }^{2}$ University Paulista Unip and Educational Institute Asafe, Brazil \\ *Corresponding author: Silvio José Gobbi, Faculty of Technology, University of Brasilia- UnB, Brazil
}

\begin{abstract}
ARTICLE INFO
Received: 慧 January 26, 2019

Published: 慧 February 12, 2019

Citation: Silvio José Gobbi, Vagner João Gobbi, Ynglid Rocha. Requirements for Selection/Development of a Biomaterial. Biomed J Sci \& Tech Res 14(3)-2019. BJSTR. MS.ID.002554.
\end{abstract}

Keywords: Biomaterial; Wear; Biocompatibility; Mechanical Biocompatibility

\begin{abstract}
A biomaterial helps to improve the quality of life and longevity of humans. Over the last decades it has become clear that the demand for biomaterials has increased rapidly due to the aging population that occurs in practically all the countries of the world, with the elderly being at higher risk of hard tissue insufficiency. Biological and mechanical biocompatibility of metal biomaterials requires much improvement. It is sought to achieve a longer shelf life of the implant biomaterial or that it lasts until the end of life without failures or need for revision surgery. Biomaterials must meet several criteria, such as excellent biocompatibility, adequate mechanical compatibility, high corrosion and wear resistance. The present work aims to perform a description of biomaterials and some properties for their choice, evidencing some characteristics of the biomaterial of titanium and its alloys.
\end{abstract}

\section{Introduction}

A biomaterial is essentially a material that is used and adapted for a medical application [1]. Although several definitions are employed to describe them, biomaterials are natural or synthetic materials that are useful for the restoration of damaged body parts, through interaction with living systems [2,3]. These materials are used to replace a component of the human body or to support physiological functions. As such, biomaterials interact with human cells, tissues or organs and sometimes even perform their functions [2]. Biomaterials are used for functional restoration engineering of different tissues to improve human health and quality of life [2]. We also find the term "nano biomaterial" that comes from the combination of biomaterial and nanotechnology [4]. The most important factor that distinguishes a biomaterial from any other material is the ability to exist in contact with the tissues of the human body without causing an unacceptable degree of damage to that body. The way in which mutually acceptable coexistence of biomaterials and tissues is developed and sustained has been of interest to biomaterial scientists and users of medical devices for many years [5]. Over the past fifty years, biomaterials science has investigated different types of biomaterials and their applications to replace or restore the function of compromised or degenerate tissues or organs [2].

Every year, more than 13 million prosthetics / medical devices are implanted in the US alone [2,6]. Biomaterials are used in different parts of the human body such as artificial valves in the heart, stents in blood vessels, replacement implants in the shoulders, knees, hips, elbows, ears and orthodontics structures. The main required property of a biomaterial is that it does not trigger an adverse reaction when put into service, which means to be a biocompatible material. In addition, good mechanical properties, high corrosion resistance, osseointegration and excellent resistance to wear, ductility and high hardness are required [7-9]. An acceptable reason for the increase in the number of revision surgeries is due to the higher life expectancy $[7,10]$. Consequently, the scenario has changed now, due to advances in medical technology, people live longer and moreover, the prognosis should be better for those who are physically traumatized due to sports or incorrect or exaggerated exercise habits or due to traffic road accidents and other accidents. Thus, the implants are expected to act much longer or to the end of life without flaws or revision surgeries. Thus, the development of 
suitable material with high longevity and excellent biocompatibility is highly essential. Although various materials are currently in use as biomaterials, titanium alloys are rapidly emerging as the first choice for most applications [7].

Aspects to be Considered for the Selection of a Biomaterial

\section{Biological Compatibility or Biocompatibility}

Biocompatibility has traditionally been related to implantable devices that were intended to remain within an individual for a long time. For those who were developing and using the first generation of implantable devices during the years between 1940 and 1980, it became increasingly obvious that the best biological performance would be achieved with materials that were the least chemically reactive [5]. Biocompatibility is defined as the ability or capacity of the material to be used in close connection with living tissue without causing adverse effects to them [11,12]. The materials used as implants are expected to be highly non-toxic and should not cause any inflammatory or allergic reactions in the human body. The rejection of an orthopedic implant due to the toxic release of metallic ions, for example, will lead to the final failure [13]. The body parts or tissue of a patient coming into contact with the implants should avoid any physical irritation, inflammation, toxicity, mutagenic or carcinogenic action $[14,15]$.

The "fibrous capsule" that surrounds the implant is also the basis of the biocompatibility of the biomaterials, and the final stage of the implantation process is represented by this capsule, which begins when the plasma proteins come into contact or are adhered to the repair [16]. The success of biomaterials depends mainly on the reaction of the human body to the implant and this measures the biocompatibility of a material [5]. When implants are exposed to human tissues and fluids, various reactions occur between the host and the implant material and these reactions determine the acceptability of these materials by our system. Problems related to biocompatibility are

a) thrombosis, which involves blood clotting and adhesion of blood platelets to the surface of the biomaterial, and

b) encapsulation of fibrous tissue from implanted soft tissue biomaterials [7].

However, the biocompatibility of the implants also depends greatly on their corrosion behaviour $[9,17]$. Thus, the greater the corrosion of the implants, the more toxic ion rates are released into the body routinely and higher risk of adverse effects can be expected $[7,9,18]$.

The human body consists of a significant number of natural elements with water (H2O), comprising about 65 to $75 \%$ by weight of the total composition. Consequently, most of the mass of a human body contains oxygen and carbon $[13,19]$. Table 1 shows a list of elements found in the human body. Where, about $96 \%$ of the available elements are oxygen, hydrogen, carbon and nitrogen, which are the building blocks of water and proteins [9]. Additional $\sim 4 \%$ of body mass comes in the form of bone minerals and blood composed of $\mathrm{Ca}, \mathrm{P}, \mathrm{Mg}$ and extracellular fluids comprising $\mathrm{Na}, \mathrm{Cl}$ and K. As such, any implant developed on the basis of these elements would be compatible with the human body [9]. However, there are few trace elements (trace elements) that are toxic at high levels. Therefore, the appropriate composition required for the metallic implant cannot be toxic. Therefore, the implant will not release toxic metal ions, which causes inflammatory or allergic reactions in the human body [9] (Table 1).

Table 1: Elements in the human body $[13,19]$.

\begin{tabular}{|c|c|c|c|c|c|c|c|c|c|c|c|c|}
\hline \multicolumn{13}{|c|}{ Elements in the Human Body $[13,19]$} \\
\hline Element & 0 & $\mathrm{C}$ & $\mathrm{H}$ & $\mathrm{N}$ & $\mathrm{Ca}$ & $\mathrm{P}$ & K & S & $\mathrm{Na}$ & $\mathrm{Cl}$ & $\mathrm{Mg}$ & $\begin{array}{l}\text { Trace } \\
\text { element }\end{array}$ \\
\hline $\mathrm{Wt} \%$ & 65.0 & 18.5 & 9.5 & 3.3 & 1.5 & 1.0 & 0.4 & 0.3 & 0.2 & 0.2 & 0.1 & $<0.01$ \\
\hline
\end{tabular}

Biocompatibility of Titanium Alloying Element: Titanium is not found in the human body and plays no known biological role in the human body [20] and is non-toxic even in large doses [13]. When amounts of up to $0.8 \mathrm{mg}$ of titanium were ingested daily by humans, most titanium was excreted without being digested or absorbed [21]. Titanium implants are generally not rejected by the body and generally make good physical connections with the host bone. In vitro assays have shown that titanium can, however, inhibit osteogenic differentiation of mesenchymal stem cells [22] and may cause genetic changes in connective tissue [23].

Biocompatibility of Titanium Alloys: Compared with stainless steel and cobalt alloys, titanium alloys have proved to be superior in terms of biocompatibility due to their excellent corrosion resistance [13,24]. In general, 316L stainless steel shows a relatively good biocompatibility, but at a less satisfactory level than CoCrMo and titanium alloys, due to the higher corrosion rates, as outlined below [13] (Figure 1).

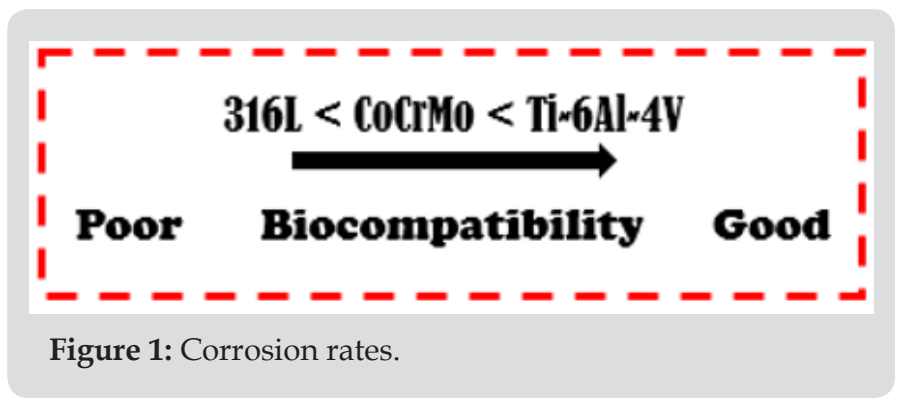


The first generation of titanium alloys, represented by the Ti-6Al-4V alloy, has been reported to cause allergic reactions to the human body [25]. The second generation of titanium alloys ( $\otimes$ titanium alloys) has been developed and investigated with great interest. Some stabilizing elements of the $\otimes$ phase, such as molybdenum, tantalum and zirconium, are used as alloying elements and are considered relatively safe when compared to vanadium and aluminum [26].

The increased use of titanium and its alloys as biomaterials comes from its superior biocompatibility and excellent corrosion resistance because of the thin layer of surface oxide and good mechanical properties such as a certain Young's modulus and low density that make these metals present a Behavior mechanic close to the bones [8]. Light, resistant and fully biocompatible, titanium is one of the few materials that naturally combine the implantation requirements in the human body $[8,25]$. In relation to titanium and its alloys, commercially pure titanium (cp Ti, grade 2) and Ti-6Al$4 \mathrm{~V}$ (grade 5) are widely used as replacements for hard tissue in artificial bones, joints and dental implants [8]. In the substitution of hard tissue (bone), as the smallest Young's modulus fits in the direction of reducing the effect of stress shielding, the low modulus of elasticity of commercially pure titanium and its alloys is usually seen as a biomechanical advantage.

Another property that makes titanium and its alloys the most promising biomaterials for implants is that titanium-based materials generally have the formation of an extremely thin and adherent protective titanium oxide film. The presence of this spontaneous oxide film in the passivation or repassivation process is an important criterion for the excellent biocompatibility and corrosion resistance of titanium and its alloys [8]. With regard to the medical applications of these materials, the use of commercially pure titanium is more limited to dental implants because of their limited mechanical properties [8]. In cases where good mechanical characteristics are required, such as in hip implants, knee implants, screws and plates, the Ti-6Al-4V alloy is widely used $[27,28]$. One of the most common applications of titanium alloys are artificial hip joints that consist of a joint bearing (head and femoral cup) and stem, where the metal cup and the components of the hip stem are made of titanium. In addition, they are also often used in knee joint replacements, which consist of a femoral and tibial component made of titanium and a polyethylene joint surface [8], as shown in Figure 2.

\section{Mechanical Compatibility}

It refers to the appropriate mechanical properties according to the function to be performed and the site to be implanted [25]. In addition, bioimplants shall have appropriate mechanical strength to withstand all forces and related loads. Primarily, the material selected for a specific application must have the ability to withstand the load, therefore, they will not be susceptible to fracture [9]. For a specific function, purpose or application, the mechanical properties determine the type of biomaterial to be chosen. Tensile strength, hardness, osseointegration, modulus of elasticity, resistance to corrosion wear are some of the properties that are of fundamental importance. Thus, if during the application the biomaterial will be subjected to repeated cyclic loads, success over the use of the implant subjected to this type of loading is determined by the fatigue strength of the material.

If an implant fractures due to inadequate resistance or divergence in mechanical properties between the bone and the implant, this is referred to as biomechanical incompatibility [7]. The bone replaced material should have a bone equivalent Young's modulus. The bone modulus varies in magnitude from 4 to $30 \mathrm{Gpa}$ depending on the type of bone and the direction of the measurement $[29,30]$. Current implant materials that have greater stiffness than the bone prevent the necessary stress from being transferred to the adjacent bone, resulting in bone resorption around the implant and, consequently, for implant loosening. This biomechanical incompatibility that leads to the death of bone cells is called the stress shielding effect [29]. Therefore, a material with excellent combination of high strength and low Young's modulus closer to the bone should be used for implantation to avoid implant loosening and longer service period, avoiding revision surgery [7].

\section{High Corrosion Resistance}

The biomaterials are normally exposed to the critical level of humidity and in environment with high percentage of localized corrosion [9]. The low corrosion resistance of implants in body fluid results in the release of metal ions not compatible with implants in the body [7]. It has been found that released ions cause allergic and toxic reactions [7,31]. Corroded implants in the human body cause excess of harmful and toxic metal ions such as $\mathrm{Fe}, \mathrm{Cr}, \mathrm{Ni}, \mathrm{Co}$, and Ti released into the body fluid [9,32]. Initially, these main trace elements in metallic implants would not be harmful by the released ions. However, when implants begin to corrode, these trace elements aggressively diffuse into the body. Excessive release of these harmful metal ions may cause adverse effects to the human body [9]. When the oxide layer on the metal is broken, corrosion occurs, and a metal ion is released. The outer layer is then passivated in a process known as regeneration. The regeneration time or repassivation time of the surface oxide layer is different for various applied materials [13]. The rate of corrosion and the release of some metal ions are highly dependent on the regeneration time [33].

The regeneration time for various alloys was observed based on the formation of surface oxide layers as shown in Figure 3. From the observation of these alloys, the regeneration time for SS $316 \mathrm{~L}$ is longer compared to the CoCrMo and Ti-6Al-4V alloys. Figure 2 indicates that SS 316L released a higher number of ions compared to the CoCrMo and Ti-6Al-4V alloys [33]. Thin layer formation through surface modification improves the biocompatibility performance with wear resistance and corrosion resistance [9] (Figure 3). In 
general, in the in vivo studies, the general conclusion is that the presence of metal ions in the body leads to biological responses [32]. Although the release of metal by corrosion and wear can be considered in principle to be very limited, the accumulation of longterm metal ions and particles in the human body is of great concern. The presence of metallic ions in the tissues around implants has been reported to cause carcinogenicity, hypersensitivity, allergy, local tissue toxicity, inflammation and genotoxicity. Thus, the development of implants with high resistance to corrosion and wear is of prime importance for the longevity of the material in the human system [7].

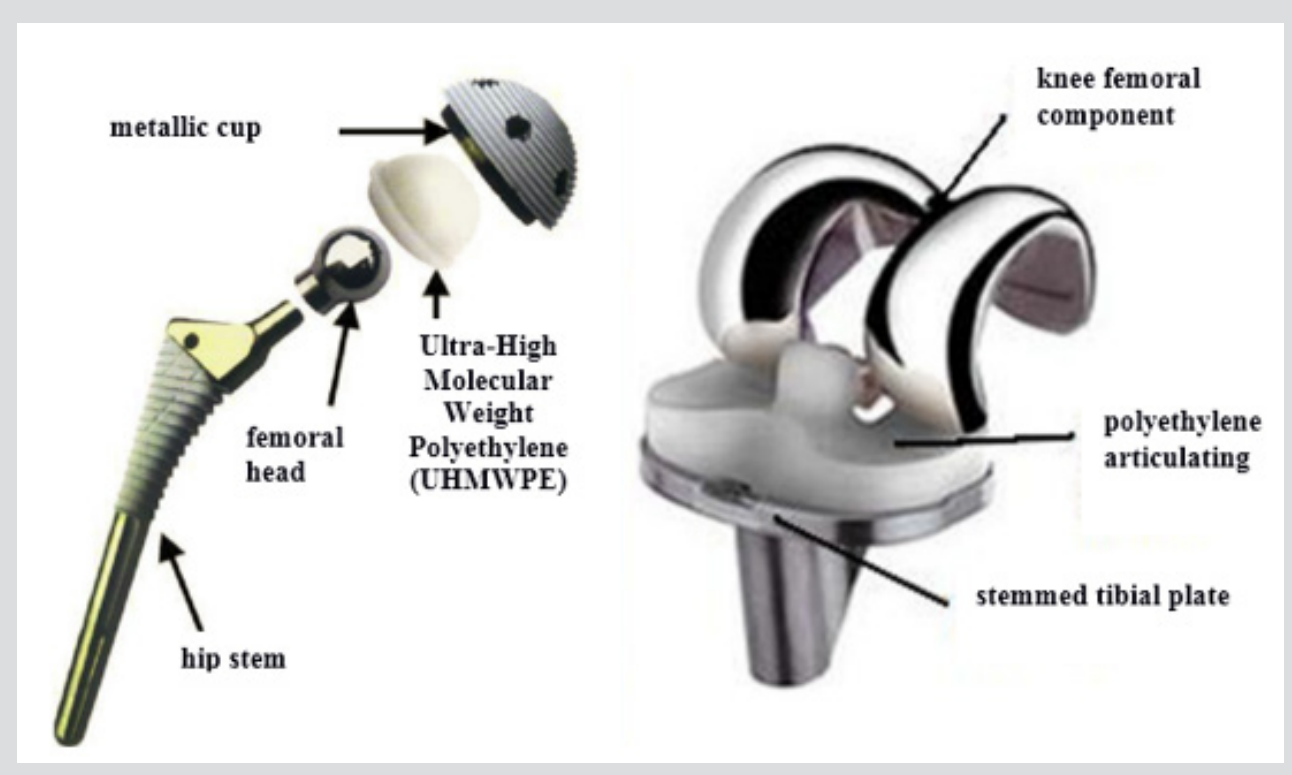

Figure 2: Schematic diagram of the artificial hip joint and knee implant.

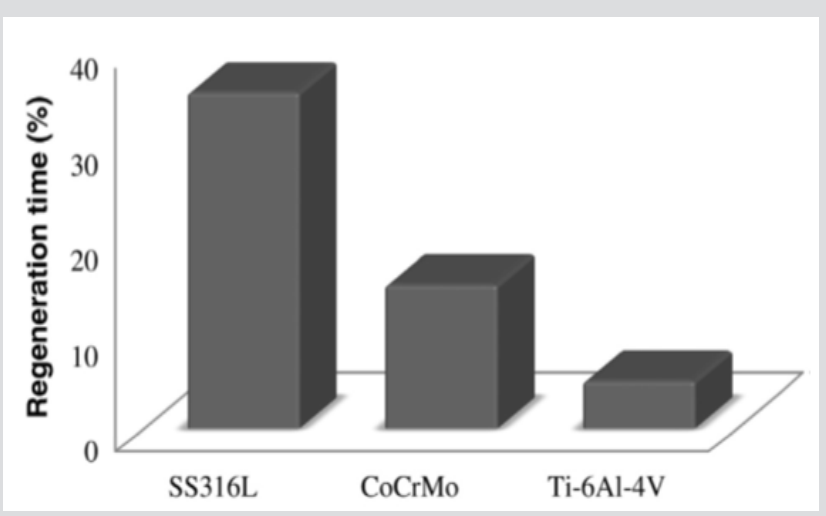

Figure 3: Time required for regeneration of surface oxide layers for some alloys [9].

\section{High Wear Resistance}

The low wear resistance leads to the release of implant wear debris into the surrounding tissue and can produce an adverse cellular response leading to the release of harmful enzymes, inflammation, osteolysis, infection, pain and bone resorption $[7,34]$. The wear resistance of the material plays a significant role in the proper functioning of the biomaterial, avoiding loosening of the implant and reactions in the tissue in which it is deposited, improving the quality of life of the patient [35]. A description of the importance of wear performance of metal biomaterials was carried out in previous work by the present authors [35].

\section{Osseointegration}

It is defined as the direct anchoring of an implant by the formation of bone tissue around the implant without fibrous tissue growth at the bone-implant interface [36,37]. Osseointegration is the stable and functional union between the bone and an implanted surface. This phenomenon occurs after insertion of the device into the bone and migration of the bone cells to the surface of the bone [38]. The osseointegration of a bone fixation is defined as the intimate apposition of newly formed bone and reformed in congruence with the fixations, including surface irregularities, so that, with the analysis by optical microscopy, there is no interposition of connective or fibrous tissue and is established a direct structural and functional connection, able to withstand normal physiological loads without excessive deformation and without initiating a rejection mechanism [28]. However, the term osseointegration can be defined considering several points of view: scientific and under the patient's eye [39]. From the point of view of patient's, an implant is osseointegrated if it provides a stable and seemingly immobile support of a prosthesis under functional loads without pain, inflammation or loosening.

From the point of view of macroscopic and microscopic biology and medicine, osseointegration of an implant in the bone is defined as the intimate apposition of newly formed bone, including surface irregularities, so that, by optical microscopy analysis, there is no interposition of connective tissue or fibrosis, and a direct structural 
and functional connection is established, capable of withstanding normal physiological loads without excessive deformation and without initiating a rejection mechanism. From the macroscopic biomechanical point of view, an implant is osseointegrated if there is no increase in mobility between the implant and the living bone and surrounding bone marrow under levels and types of functional load throughout the life of the patient. It is also necessary that the deformations are of the same order of magnitude as when the same loads are applied directly to the bone. From a microscopic biophysical point of view: osseointegration implies that, in optical and electron microscopy, the identifiable components of tissue in a thin zone around the surface of the implant are identified as normal bone and spinal components, which continually constitute a normal bone structure around the fixation. This implies that the mineralized tissue must be in contact with nanometres, so that there is no significant material interfaced functionally at the interface [39].

\section{Final considerations}

The discussion mentioned above illustrates that for choosing a biomaterial one must observe some fundamental properties according to the specific application to be performed by the implant. Biocompatibility is the basic point of choice, and titanium alloys are superior in terms of compatibility compared to stainless steel and cobalt alloys. High wear resistance prevents implant loosening, adverse reactions and revision surgery. A biomaterial should not present mechanical incompatibility, having a modulus of elasticity equivalent to that of bone avoiding the effect of stress shielding. It must also have high corrosion resistance avoiding the release of non-compatible metallic ions from the implant to the body. In all biomaterial selection and development, the objective is the longevity of the implant in the living organism and a better quality of life of the patient.

\section{References}

1. Tathe A, Ghodke M, Nikalje, AP (2010) A Brief Review: Biomaterials and Their Apllication. Int J Pharm Pharm Sci 2(4): 19-23.

2. Bose S, Ke D, Sahasrabudhe H, Bandyopadhyay, A (2017) Additive Manufacturing of Biomaterials. Progress in Materials Science 93: 45111.

3. Ebrahimi M (2018) Biomaterials Application in Therapeutic and Regenerative Medicine from the Perspective of Patients' Faith. BJSTR 8(5): 1-3.

4. Kazemipoor M (2017) Application of Nanobiomaterials in Endodontics. Biomed J Sci \& Tech Res 1(7): 1-3.

5. Williams DF (2008) On the mechanisms of biocompatibility. Biomaterials 29(20): 2941-2953.

6. Wang X (2013) Overview on Biocompatibilities of Implantable Biomaterials. Advances in Biomaterials Science and Biomedical Applications pp. 111-155.

7. Geetha M, Singh AK, Asokamani R, Gogia AK (2009) Ti based biomaterials, the ultimate choice for orthopaedic implants- A review. Progress in Materials Science 54(3): 397-425.

8. Viteri VS, Fuentes H (2013) Titanium and Titanium Alloys as Biomaterials. Tribology Fundamentals and Advancements pp. 155-181.
9. Asri RI, Harun WS, Lah NA, Ghani SA, M Samykano, et al. (2017) Corrosion and surface modification on biocompatible metals: A review. Materials Science and Engineering: C 77(1): 1261-1274.

10. Gepreel MA, Niinomi M (2013) Biocompatibility of Ti-alloys for longterm implantation. J Mech B Materials 20: 407-415.

11. Hedberg YS, Qian B, Shen Z, Virtanen S, Wallinder IO (2014) In vitro biocompatibility of CoCrMo dental alloys fabricated by selective laser melting. Dental Materials 30(5): 525-534.

12. Plummer DR, Berger RA, Paprosky W G, Sporer SM, Jacobs JJ, et al. (2016) Diagnosis and management of adverse local tissue reactions secondary to corrosion at the head-neck junction in patients with metal on polyethylene bearings. The Journal of Arthroplasty 31(1): 264-268.

13. Chen Q Thouas GA (2015) Metallic implant biomaterials. Materials Science and Engineering R 87: 1-57.

14. Freire WP, Fook MV, Barbosa EF, Camila dos S. Araújo, Rossemberg C. Barbosa, et al (2015) Biocompatibility of dental restorative materials. Materials Science Forum 805: 19-25.

15. Fathi MH, Salehi M, Saatchi A, VMortazavi, S B Moosavi (2003) In vitro corrosion behavior of bioceramic, metallic, and bioceramic-metallic coated stainless-steel dental implants. Dental Materials19(3): 188-198.

16. Gottfried L (2018) Biocompatibility of Injectable Microspheres. Biomed J Sci \&Tech Res 2(1): 1-11.

17. Agarwal S, Curtin J, Duffy B, Jaiswal S (2016) Biodegradable magnesium alloys for orthopaedic applications: a review on corrosion, biocompatibility and surface modifications. Materials Science and Engineering: C 68: 948-963.

18. Dorozhkin SV (2014) Calcium orthophosphate coatings on magnesium and its biodegradable alloys. Acta Biomaterialia 10(7): 2919-2934.

19. Underwood E (2012) Trace Elements in Human and Animal Nutrition. Elsevier pp. 347.

20. Pais I, Feher M, Farkas E, Szabo Z (1977) Titanium as a new trace element. C. in Soil Science and Plant Analysis 8(5): 407-410.

21. Yaghoubi S, Schwietert CW, Mccue JP (2000) Biological Roles of Titanium. Biological Trace Element Research 78(1-3): 205-217.

22. Wang ML, Tuli R, Manner PA, Sharkey PF, Hall DJ, et al. (2003) Direct and indirect induction of apoptosis in human mesenchymal stem cells in response to titanium particles. Journal of Orthopaedic Research 21(4): 697-707.

23. Coen N, Kadhim MA, Wright EG, Case CP, Mothersill CE (2003) Particulate debris from a titanium metal prosthesis induces genomic instability in primary human fibroblast cells. British Journal of Cancer 88(4): 548552 .

24. Lemons JE, Niemann KM, Weiss AB (1976) Biocompatibility studies on surgical-grade titanium-, cobalt-, and iron-base alloys. Journal of Biomedical Materials Research 10(4): 549-553.

25. Niinomi M (2008) Mechanical biocompatibilities of titanium alloys for biomedical applications. Journal of the Mechanical Behavior of Biomedical Materials 1(1): 30-42.

26. Niinomi M (2002) Recent Metallic Materials for Biomedical Applications. Metallurgical and Materials Transactions A 33A: 477- 486.

27. Stadlinger B, Ferguson SJ, Eckelt U, RolandMai, Anna TheresaLode, et al. (2012) Biomechanical evaluation of a titanium implant surface conditioned by a hydroxide ion solution. British Journal of Oral and Maxillofacial Surgery 50(1): 74-79.

28. Subramani K, Mathew R (2012) Titanium Surface Modification Techniques for Dental Implants - From Microscale to Nanoscale. Emerging Nanotechnologies in Dentistry pp. 85-102.

29. Al-tamimi AA, Peach C, Fernandes PR, Akos Csekea, Paulo JDS Bartolo (2017) Topology Optimization to reduce the stress shielding effect for orthopedic applications. Procedia CIRP 65: 202-206. 
30. Murr LE (2017) Open-cellular metal implant design and fabrication for biomechanical compatibility with bone using electron beam melting. Journal of the Mechanical Behavior of Biomedical Materials 76: 164-177.

31. Hallab N, Anderson S, Stafford TG, Jacobs JJ, Glant T (2005) Lymphocyte responses in patients with total hip arthroplasty. Journal of Orthopaedic Research 23(4): 384-391.

32. Espallargas N, Torres C, Muñoz AL (2015) A metal ion release study of CoCrMo exposed to corrosion and tribocorrosion conditions in simulated body fluids. Wear 332-333: 669-678.

33. Hanawa T (1999) In vivo metallic biomaterials and surface modification. Materials Science and Engineering A 267(2): 260-266.

34. Li SJ, Yang R, Li, Hao YL, Cui YY, et al. (2004) Wear 257: 869-876.

35. Gobbi SJ, Gobbi VJ (2018) Wear Resistance of Metallic Orthopedic Implants - Mini Review. Biomed J Sci \& Tech Res 12(3): 1-2.

ISSN: 2574-1241

DOI: 10.26717.BJSTR.2019.14.002554

Silvio José Gobbi. Biomed J Sci \& Tech Res

(C) (-) This work is licensed under Creative

Submission Link: https://biomedres.us/submit-manuscript.php
36. Albrektsson T, Branemark PI, Hansson HA, Lindström J (1981) Osseointegrated titanium implants. Requirements for ensuring a longlasting, direct bone-to-implant anchorage in man. Acta Orthopaedica Scandinavica 52(2): 155-170.

37. Carlsson L, Rostlund T, jörn Albrektsson, Tomas Albrektsson, Per Ingvar Brånemark (1986) Osseointegration of titanium implants. Acta Orthopaedica Scandinavica 57(4): 285-289.

38. Nasab MB, Hassan MR, Sahari BB (2010) Metallic Biomaterials of Knee and Hip - A Review. Trends Biomater. Artif. Organs 24(2): 69-82.

39. Brånemark PI, Rydevik BL, Skalak R (1997) Osseointegration in skeletal reconstruction and joint replacement. Carol Stream, IL: Quintessence Publishing Co p. 25-44.

$\begin{array}{ll}\text { BIOMEDICAL } & \text { Assets of Publishing with us } \\ \text { RESEARCHES } & \text { - Global archiving of articles } \\ & \text { - Immediate, unrestricted online access } \\ & \text { - Rigorous Peer Review Process } \\ & \text { - Authors Retain Copyrights }\end{array}$

